\title{
A Well-Controlled Nucleus Pulposus Tissue Culture System with Injection Port for Evaluating Regenerative Therapies
}

\author{
Irene T. M. Arkesteijn, ${ }^{1}$ Vivian H. M. Mouser, ${ }^{1,2}$ Fackson Mwale, ${ }^{3}$ Bart G. M. van Dijk, ${ }^{1}$ \\ and Keita Ito ${ }^{1,2}$ \\ ${ }^{1}$ Orthopaedic Biomechanics, Department of Biomedical Engineering, Eindhoven University of Technology, PO Box 513, 5600 \\ MB Eindhoven, The Netherlands; ${ }^{2}$ Department of Orthopaedics, University Medical Center Utrecht, Utrecht, The Netherlands; \\ and ${ }^{3}$ Division of Orthopaedic Surgery, Lady Davis Institute for Medical Research, McGill University, Montreal, Canada
}

(Received 30 April 2015; accepted 11 August 2015; published online 21 August 2015)

Associate Editor Amit Gefen oversaw the review of this article.

\begin{abstract}
In vitro evaluation of nucleus pulposus (NP) tissue regeneration would be useful, but current systems for NP culture are not ideal for injections. The aim of this study was to develop a long-term culture system for NP tissue that allows injections of regenerative agents. Bovine caudal NPs were harvested and placed in the newly designed culture system. After equilibration of the tissue to $0.3 \mathrm{MPa}$ the volume was fixed and the tissue was cultured for 28 days. The cell viability and extracellular matrix composition remained unchanged during the culture period and gene expression profiles were similar to those obtained in earlier studies. Furthermore, to test the responsiveness of bovine caudal NPs in the system, samples were cultured for 4 days and injected twice (day 1 and 3) with (1) PBS, (2) Link-N, for regeneration, and (3) TNF- $\alpha$, for degeneration. It was shown that TNF- $\alpha$ increased COX2 gene expression, whereas no effect of Link-N was detected. In conclusion, the newly designed system allows long-term culture of NP tissue, wherein tissue reactions to injected stimulants can be observed.
\end{abstract}

Keywords-Intervertebral disc, Regeneration, In vitro, Link$\mathrm{N}, \mathrm{TNF}-\alpha$.

\section{INTRODUCTION}

Intervertebral discs support high magnitude loads and allow multi-directional flexibility in the spine, due to an ingenious interplay of the tissues within the disc. The highly hydrated nucleus pulposus (NP) evenly distributes compressive stresses to the organized

Address correspondence to Bart G. M. van Dijk, Orthopaedic Biomechanics, Department of Biomedical Engineering, Eindhoven University of Technology, PO Box 513, 5600 MB Eindhoven, The Netherlands. Electronic mails: i.t.m.arkesteijn@tue.nl, v.h.m. mouser@umcutrecht.nl, fmwale@1di.jgh.mcgill.ca, b.g.m.v.dijk@ tue.nl, k.ito@tue.nl annulus fibrosus (AF), which balances these with internal tensile stresses. ${ }^{31}$ The human NP starts to degenerate early in adulthood, resulting in a non-uniform stress distribution, subsequent disorganization and disruption of the AF, and potentially pain. ${ }^{36}$ It has been suggested that early stage NP regeneration could halt this degenerative cascade. ${ }^{12}$ Biological therapies for NP regeneration aim at restoring the water and proteoglycan content of the tissue. For this purpose exogenous cells, to produce extracellular matrix, and molecular agents or gene therapy, to increase the matrix production by resident cells, can be introduced into the tissue. ${ }^{12}$ However promising, these methods still face challenges and require more extensive testing.

Currently, the most widely used model to test regenerative therapies is the in vivo animal model. Its main advantage is the presence of all natural interactions of the organism. However in most test cases, rodents or other small animals are used in which degeneration is artificially induced. First of all, such small animals have a mature nuclear cell type, which is different than that of humans. ${ }^{1}$ Second, the artificially induced degeneration is different from the human pathophysiological degenerative cascade. Thus, translation of results obtained in studies with artificial degeneration to naturally degenerated human NPs is difficult. $^{2}$ Testing regenerative therapies on in vitro cultured cells is another standard method. However, cell metabolism and phenotype outside of the native matrix and environment change. ${ }^{9}$ Hence, tissue culture models are of great interest.

Although both organ and NP tissue culture models are available, long-term organ cultures are still under development. ${ }^{4,10}$ As the evaluation of regenerative therapies 
often requires long-term studies, we focused on optimizing currently available NP culture systems. The advantage of the NP culture system is the presence of cell-matrix interactions in a controlled culture environment. In standard culture conditions NP tissue does not thrive in the long-term, because it swells tremendously. Previously designed culture systems for NP explants have demonstrated that the tissue matrix can be maintained when it is physically constrained. ${ }^{11,30}$ Furthermore, when explants were cultured at physiological oxygen, $\mathrm{pH}$ and glucose levels for 42 days, matrix protein gene expression was nearly preserved. ${ }^{30}$ However, our existing system has two major drawbacks: the swelling pressure cannot be standardized, limiting the reproducibility, and repeated administration of injections is not feasible, as these damage the culture system.

Therefore, the aim of this study is to design and develop a novel NP culture system, which allows prevention of tissue swelling in a controlled manner and repeated injections of regenerative agents. It was hypothesized that bovine NP tissue, when first equilibrated to a physiological pressure of $0.3 \mathrm{MPa}^{33}$ in this new system, is responsive to injected stimuli. In a first experiment, NP tissue was cultured long-term to test the maintenance of the extracellular matrix and gene expression in the system. Then, the response to injections of regenerative peptide Link-N or inflammatory cytokine TNF- $\alpha$ was evaluated in a short-term experiment.

\section{MATERIALS AND METHODS}

\section{Culture System Design}

To limit tissue swelling, a system was designed to physically constrain NP tissue in a custom-made hol- low cylinder (polyether ether ketone; PEEK) with two porous stainless steel plates (sintered $316 \mathrm{~L}$ stainless steel; pores $0.5 \mu \mathrm{m}$ ) that allow for molecular transport (Fig. 1). Prior to culture, the position of the upper porous plate, and herewith the tissue's volume, was set by applying an axial load until equilibrium was reached (Fig. 2). In these experiments, a pressure of $0.3 \mathrm{MPa}$ was applied, and after equilibration $(24 \mathrm{~h})$, the position of the upper porous plate was locked. Furthermore, the cylindrical container has an injection port on the side, which can be (re-)closed with a screw.

\section{Culture System Validation}

Fresh bovine tails ( 24 months old) were obtained from the abattoir according to local regulations. Adjacent to the endplates, the discs (Cy1-Cy5) were opened transversally, and a biopsy punch (ø $8 \mathrm{~mm}$; 273693, Kruuse, Sherburn, UK) was used to harvest tissue from the center of the disc (180-220 mg). NP tissue biopsies were placed in the culture system and equilibrated. After equilibration and subsequent fixation of the tissue volume, the system was placed in a plastic container $(60 \mathrm{~mL}$ medium) with a lid made of a gas permeable silicone membrane (MED82-5010-10, NuSil, Carpinteria, USA) and cultured at $37{ }^{\circ} \mathrm{C}, 5 \%$ $\mathrm{O}_{2}$ and $5 \% \mathrm{CO}_{2}$. Culture medium consisted of advanced DMEM (12491-015, Invitrogen, Bleiswijk, the Netherlands) supplemented with $10 \%$ fetal bovine serum (758093, Greiner Bio-one, Alphen a/d Rijn, the Netherlands) and 1\% penicillin/streptomycin (DE17602E, Lonza, Basel, Switzerland) and was changed twice a week.

To assess long-term culture potential, bovine tails of eight donors were used to obtain eighteen NP samples,
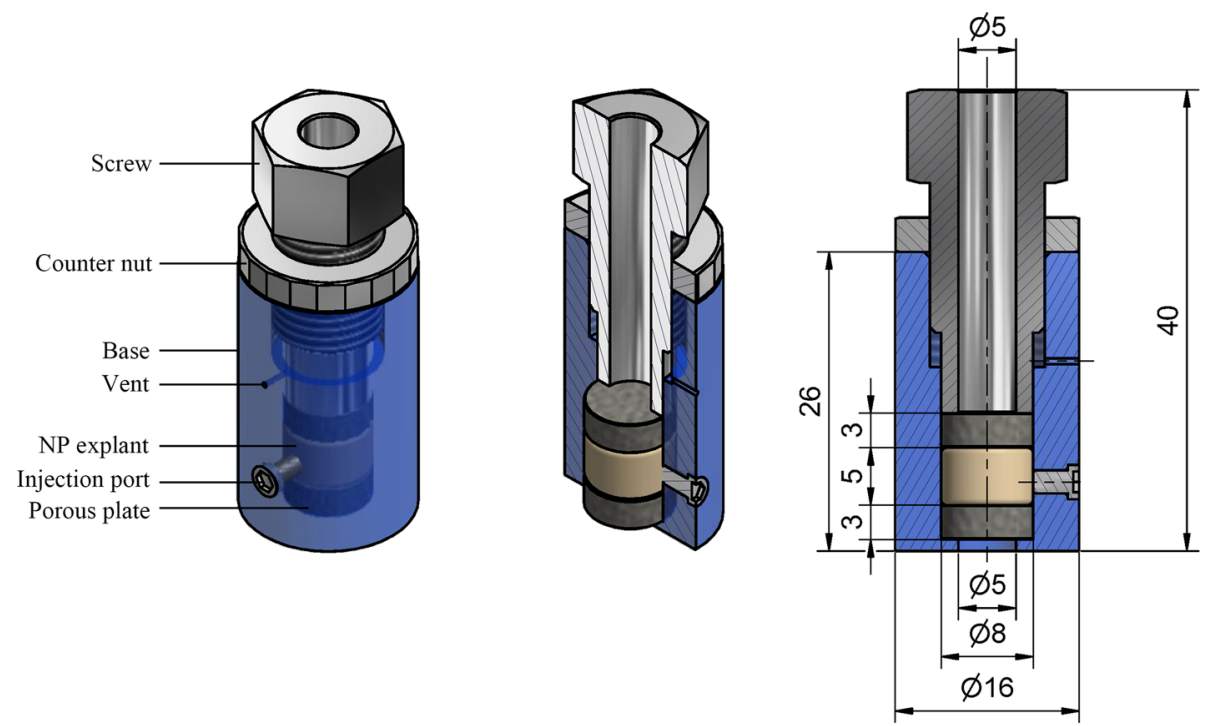

FIGURE 1. Culture system design. 


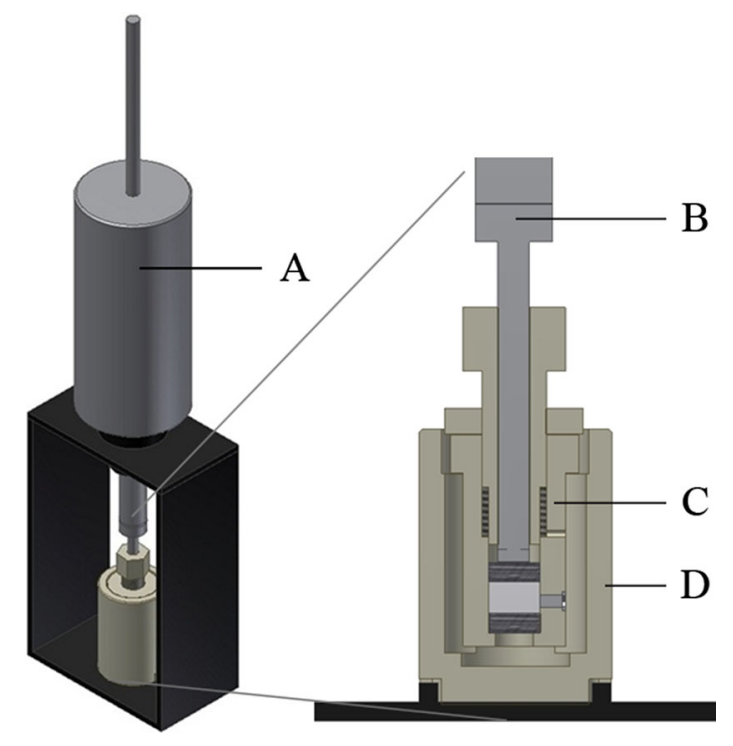

FIGURE 2. Axial load system design. The axial load system consists of the following components: (a) (replaceable) weight, (b) transmission of load to the upper sintered stainless steel plate, (c) culture system as described in Fig. 1, (d) reservoir for culture medium.

which were randomly distributed (disc level and donor) over the following groups:

a. Day 0, collected immediately after harvesting,

b. Day 1, collected after equilibration, and

c. Day 28 , collected after 28 days of culture.

For each group, 6 samples (corresponding to 6 donors) were used. The biochemical and water content ( $1 / 4$ sample), histology and cell viability ( $1 / 2$ sample) and gene expression ( $1 / 4$ sample) were analyzed.

To visualize injections, bovine tails of three donors were used to obtain six NP samples, which were injected with $10 \mu \mathrm{L} 0.1 \%$ Picrosirius red (36.554-8, Sigma, Zwijndrecht, the Netherlands) with a 32 gauge needle (7635-01/00, Hamilton, Bonaduz, Switzerland). Samples were collected 1,5 or $17 \mathrm{~h}$ after injection ( $n=2 /$ group) to assess diffusion of the dye throughout the tissue.

To assess tissue responsiveness to injected agents bovine tails of nine donors were used to obtain fourteen NP samples, which were randomly distributed (disc level and donor) over the following groups:

a. Sham, injected with $10 \mu \mathrm{L}$ of phosphate buffered saline (PBS; $n=4$ ),

b. Link- $N$, injected with $10 \mu \mathrm{L}$ of $20 \mu \mathrm{g} / \mu \mathrm{L}$ Link$\mathrm{N}$ peptide (DHLSDNYTLDHDRAIH; CanPeptide Inc; Pointe Claire, QC, Canada; $n=5)$

c. $T N F-\alpha$, injected with $10 \mu \mathrm{L}$ of $0.5 \mathrm{ng} / \mu \mathrm{L}$ recombinant human tumor necrosis factor- $\alpha$ (TNF- $\alpha$; PHC3016, Invitrogen; $n=5$ ),
Injections were administered on day 1 , after equilibration, and on day 3. Samples were harvested on day 4. As injections were administered in the center of the samples, the core of each sample was obtained with a $5 \mathrm{~mm}$ biopsy punch (Kruuse), and analyzed for gene expression ( $1 / 2$ sample).

\section{Analysis}

To assess the biochemical content, samples were weighed (wet weight), lyophilized (Freezone 2.4, Labconco, Kansas City, MO, USA) overnight and then the dry weight was determined. The water content was calculated by dividing the difference between wet and dry weight by the wet weight. Subsequently, the samples were digested overnight in a papain digestion buffer $(100 \mathrm{mM}$ phosphate buffer, $5 \mathrm{mM}$ L-cystein, $5 \mathrm{mM}$ ethylenediaminetetraacetic acid and $140 \mu \mathrm{g} / \mathrm{mL}$ papain, all from Sigma) at $60{ }^{\circ} \mathrm{C}$. The DNA content of the digested sample was measured with a Hoechst dye assay $^{3}$ and calf thymus DNA as reference (D3664, Sigma). The glycosaminoglycan (GAG) content was used as a measure for the amount of proteoglycans. The GAG content was determined with a DMMB assay, ${ }^{5}$ using shark cartilage chondroitin sulfate (C4384, Sigma) as reference. The fixed charge density (FCD) was calculated from the GAG per wet weight, as described by Narmoneva et al. ${ }^{19}$ The hydroxyproline (HYP) content was measured with a chloramin-T assay $^{8}$ using trans-4-hydroxyproline (H5534, Sigma) as reference.

For histology, samples were snap-frozen in TissueTek O.C.T. compound (4583, Sakura Finetek, Zoeterwoude, the Netherlands) in isopentane in liquid $\mathrm{N}_{2}$ and stored at $-30{ }^{\circ} \mathrm{C}$ until further use. $10 \mu \mathrm{m}$ thick sections were cut (Microm, Thermo Fisher Scientific, Kalamazoo, MI, USA) to assess cell viability and histology. Lactate dehydrogenase (LDH) staining (N5514, Sigma) to stain living cells dark, as described by Stoddart et al. ${ }^{28}$ was used in combination with propidium iodide staining (P3566, Invitrogen) to mark all DNA red-fluorescent to assess the cell viability and distribution. Extracellular matrix was stained with Weigert's hematoxylin for nuclei, Safranin-O (84120, Fluka, Sigma) for proteoglycans and Fast Green (1.00056.2500, Merck, Darmstadt, Germany) for collagen. Bright field images were made of Safranin-O/ Fast Green and LDH sections, while fluorescent images were taken for the LDH staining (Observer, Zeiss, Sliedrecht, the Netherlands).

To measure the gene expression, samples were snapfrozen and stored at $-80{ }^{\circ} \mathrm{C}$ until further use. Messenger RNA (mRNA) extraction was done as described by van Dijk et al. ${ }^{30}$ The concentration of RNA was determined with a spectrophotometer (ND-1000, 
TABLE 1. List of primers for gene expression analysis.

\begin{tabular}{|c|c|c|}
\hline Gene & Accession number & Oligonucleotide sequence $\left(5^{\prime} \rightarrow 3^{\prime}\right)$ \\
\hline \multirow[t]{2}{*}{ ACAN } & NM_173981 & F: CCAACGAAACCTATGACGTGTACT \\
\hline & & R: GCACTCGTTGGCTGCCTC \\
\hline \multirow[t]{2}{*}{ COL1 } & NM_001034039 & F: TGAGAGAGGGGTTGTTGGAC \\
\hline & & R: GGGAGACCATTGAGTCCATC \\
\hline \multirow[t]{2}{*}{ COL2 } & NM_001113224 & F: TGGCTGACCTGACCTGAC \\
\hline & & R: GGGCGTTTGACTCACTCC \\
\hline \multirow[t]{2}{*}{ MMP13 } & NM_174389 & F: CCTTGATGCCATAACCAGTCTCC \\
\hline & & R: ATCAATACGGTTGGGAAGTTCTGG \\
\hline \multirow[t]{2}{*}{ TIMP1 } & NM_174471 & F: GTCAATGAAACTGCCTTATACC \\
\hline & & R: TTCTGGGACCTGTGGAAG \\
\hline \multirow[t]{2}{*}{ TIMP2 } & NM_174412 & F: GCAACGACATCTACGGCAACC \\
\hline & & R: CCCACACACGGCAGAGGAG \\
\hline \multirow[t]{2}{*}{$\operatorname{cox} 2$} & NM_174445 & F: TCCACCAACTTATAATGTGCAC \\
\hline & & R: GGCAGTCATCAGGCACAGGA \\
\hline \multirow[t]{2}{*}{ GAPDH $^{*}$} & NM_001034034 & F: GGCGTGAACCACGAGAAGTATAA \\
\hline & & R: CCCTCCACGATGCCAAAGT \\
\hline $18 s^{*}$ & (Primer Design Ltd) & \\
\hline
\end{tabular}

${ }^{*}$ Reference gene.

ACAN = aggrecan; COL1/COL2 = collagen type I/II; MMP13 = matrix metalloprotease 13; TIMP1/TIMP2 = tissue inhibitor of metalloproteinase 1/2; COX2 = cyclooxygenase 2 ; GAPDH = glyceraldehydes-3-phosphate dehydrogenase.

Isogen, de Meern, the Netherlands). In total, $63 \mathrm{ng}$ of mRNA was used for cDNA synthesis (VILO kit, Invitrogen). Gene expression was analyzed in a real time polymerase chain reaction (qPCR, CFX384, BioRad, Veenendaal, the Netherlands) using the SYBR Green Supermix (Bio-Rad). Three reference genes [18s (PrimerDesign, Southampton, UK), glyceraldehyde-3phosphate dehydrogenase (GAPDH), and RPL13a] were evaluated in each experiment, and the most stable one was selected as reference gene. For the long-term culture $18 \mathrm{~s}$ was selected and for the short-term tissue response experiment $G A P D H$. The genes of interest were aggrecan $(A C A N)$, collagen type I $(C O L 1)$, collagen type II (COL2), matrix metalloprotease 13 (MMP13), tissue inhibitor of metalloproteinase 1 and 2 (TIMP1, TIMP2) for both experiments. Additionally, cyclooxygenase $2(C O X 2)$ was tested in the shortterm tissue response experiment. Primer sequences are provided in Table 1. Levels of expression were determined using the $\Delta \mathrm{Ct}$ method $^{13}$ and $\mathrm{Ct}$ values were normalized to the selected reference gene.

To visualize picrosirius injections, samples were entirely snap-frozen in Tissue-Tek (Sakura) after culture. $100 \mu \mathrm{m}$-thick transversal slices were cut at different heights (top, middle and bottom) of the sample to visualize (Observer, Zeiss) the distribution of the staining inside the sample.

\section{Statistics}

Statistical analysis was performed using R-project software (version 3.0.2). ${ }^{23}$ At first, all data sets were tested for group homogeneity and normal distribution with Levene's and Shapiro-Wilks' tests respectively. When homogeneous and normally distributed, a oneway ANOVA was performed with Bonferroni's corrected post hoc independent $t$ test. If data were not normal, a Kruskal-Wallis test was done with Bonferroni's corrected post hoc Mann-Whitney test. Statistical significance was assumed for $p<0.05$.

\section{RESULTS}

\section{NP Tissue is Maintained in Long-Term Culture}

The water content decreased between day 0 and day $1(p=0.003)$, which indicates that water was removed from the tissue during the equilibration phase. By tracking the change in sample height, it could be seen that the equilibrium was reached within $15 \mathrm{~h}$ (data not shown). Related to the change in water content, the FCD was higher on day 1 than on day $0(p=0.02$, Fig. 3c). However, by day 28 of culture, the water content and FCD were not significantly different from day 0 ( $p=0.30$ and $p=0.95$ respectively, Fig. 3a). The total GAG content did not change $(p=0.27$, Fig. 3b), which was corroborated with the Safranin-O/ Fast Green staining (Fig. 4). The collagen content, DNA content $(p=0.55$ and $p=0.15$ respectively, Figs. 3d and 3e), and cell viability (Fig. 4) were not different between days of culture. The mRNA expression of $A C A N$, the main extracellular matrix protein, and TIMP 2 decreased between day 0 and 28 
(a)

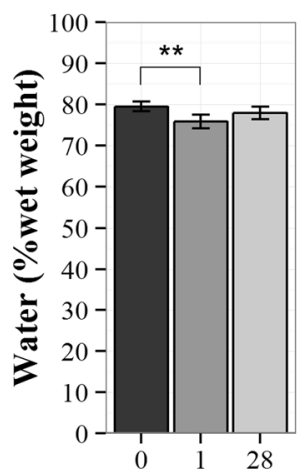

(b)

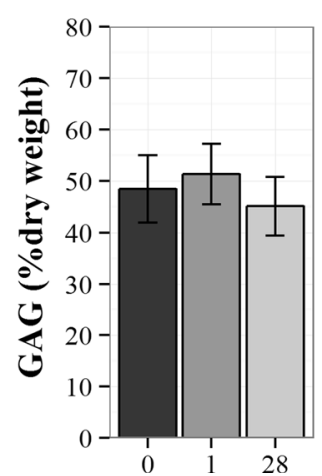

(c)

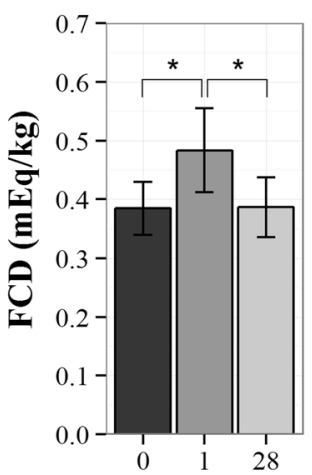

(d)

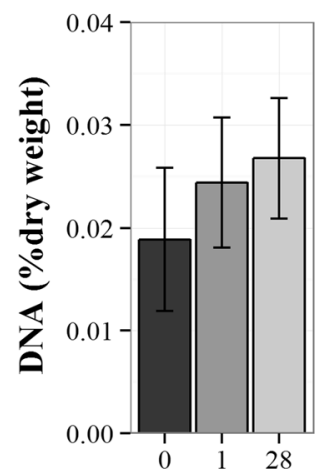

(e)

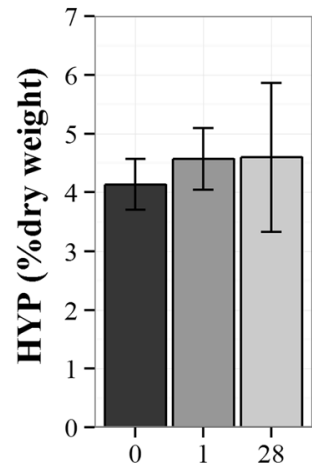

FIGURE 3. Water and biochemical content after long-term culture. (a) Water content per wet weight, (b) GAG content per dry weight, (c) fixed charged density (FCD), (d) DNA content per dry weight, and (e) hydroxyproline content per dry weight. Values are mean $\pm \mathrm{SD} ; n=6$ for each group. $X$-axis $=$ number of days in culture. ${ }^{\star} p<0.05$ and ${ }^{\star \star} p<0.005$.
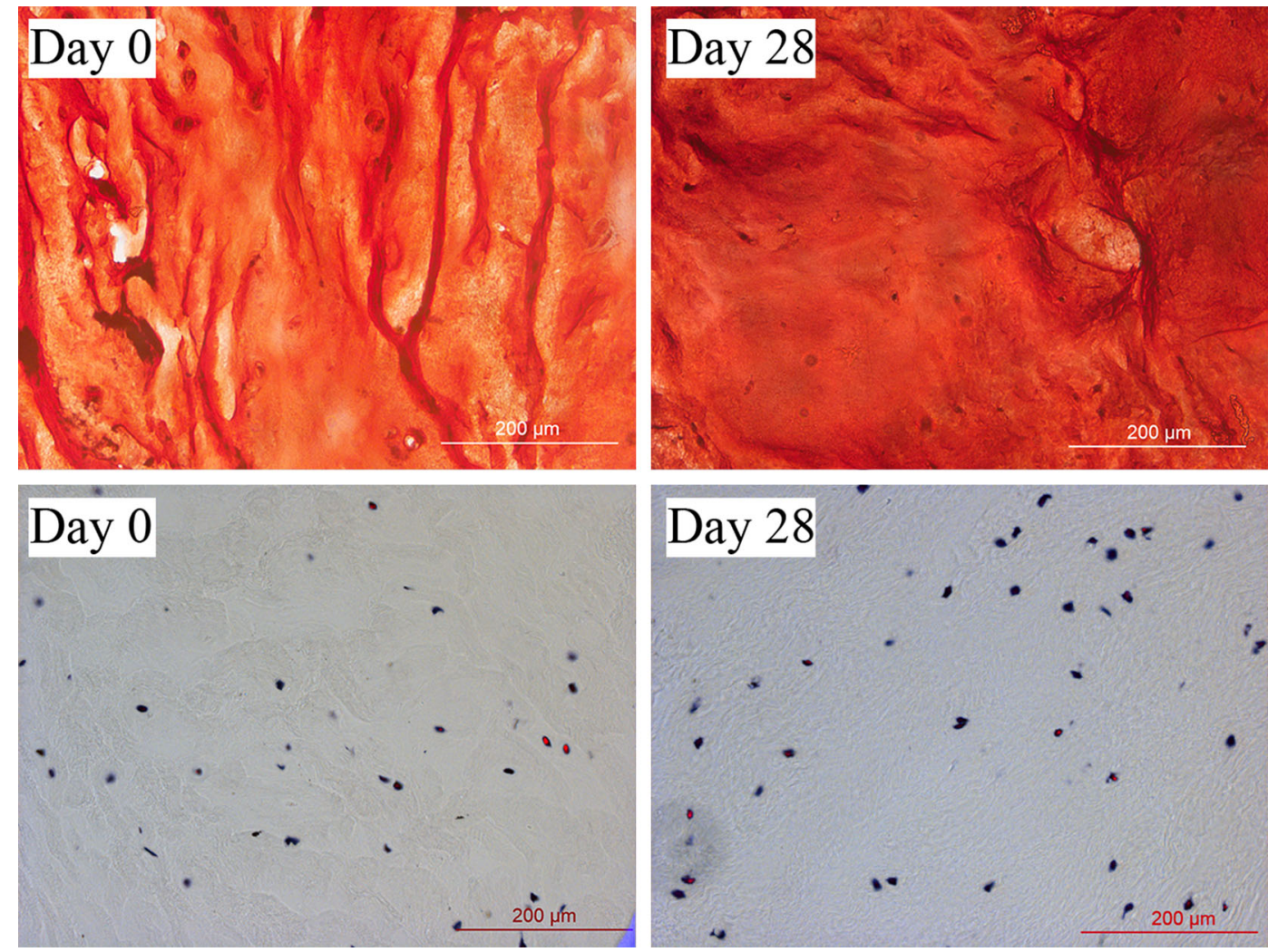

FIGURE 4. Extracellular matrix and viability staining after long-term culture. Safranin-O/Fast green and LDH staining on day 0 (left) and day 28 (right). Proteoglycans are stained red, collagen green and cell nuclei black in the upper images. Living cells are stained black and their nucleic acids red in the lower images. Scale bars are $200 \mu \mathrm{m}$.

( $p=0.005$ and $p=0.009$ respectively, Figs. 5a and $5 \mathrm{e})$, whereas $M M P 13$ expression increased in the same time frame $(p=0.03$, Fig. 5c). COL2 and TIMPI expression did not change significantly $(p=0.08$ and $p=0.21$ respectively) during the culture period (Figs. 5b and 5d), while the expression of COL1 was beyond detection limits for all samples.

\section{Injections can be Targeted}

Picrosirius red staining showed that targeting an injection in the core of the NP tissue is feasible. Time dependent picrosirius diffusion was observed, as the intensity of the color decreased in the core and increased in the surrounding areas (Fig. 6). 
(a)

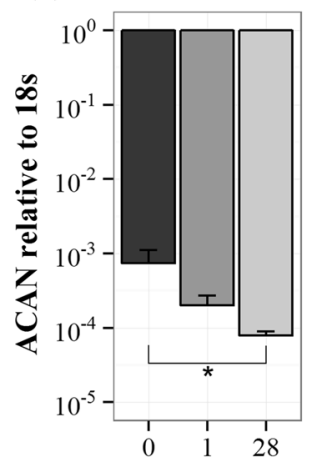

(b)

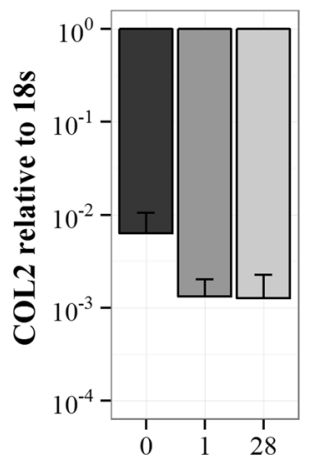

(c)

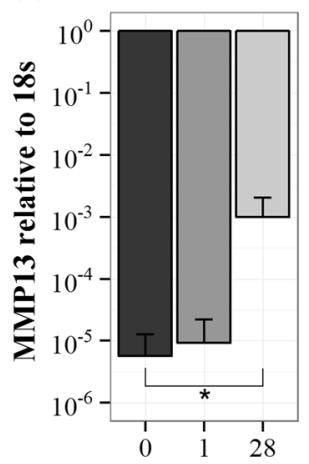

(d)

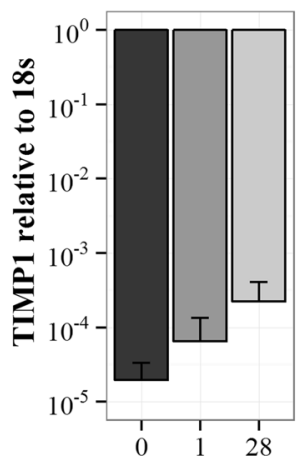

(e)

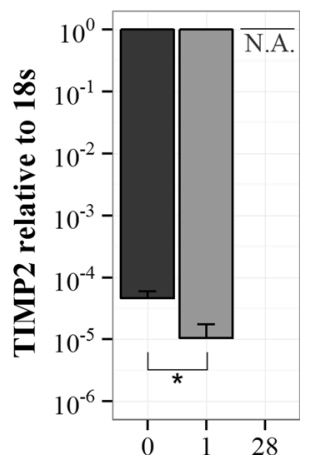

FIGURE 5. Gene expression after long-term culture. The expression of (a) aggrecan, (b) collagen type II, (c) matrix metalloprotease 13, (d) tissue inhibitor of metalloprotease (TIMP) 1, and (e) TIMP2 relative to reference gene 18s. Please note the logarithmic $\boldsymbol{y}$-axis and error bars. $X$-axis $=$ number of days in culture. Values are mean $\pm S D ; n=5$ for day 0 and $1 ; n=3$ for day 28 . ${ }^{\star} p<0.05$.

\section{NP Tissue is Responsive to TNF- $\alpha$}

COX2 expression was significantly higher in the samples injected with TNF- $\alpha$ than in the sham and Link-N groups $(p=0.02$ and $p=0.04$ respectively, Fig. 7f), which shows that NP tissue is responsive in this system. Injections of Link-N did not result in a change in gene expression when compared to the sham group (all genes, $p>0.40$; Figs. 7a-e). The expression of COL1 was beyond detection limits for all samples.

\section{DISCUSSION}

It was previously shown that constraining NP tissue maintains the extracellular matrix and mostly preserves native gene expression profiles in long-term culture. ${ }^{30}$ However, constraining of the tissue was done manually and reproducibility was less than desired. Furthermore, the actual osmolarity and hydraulic pressure in the NP were unknown. ${ }^{30}$ By controlling the initial osmotic pressure, a novel and very reproducible NP culture system was designed where a fixed tissue volume could be created as a function of the initial osmotic pressure.

Previous studies have shown adverse effects on gene expression and matrix composition if static compression of $0.4 \mathrm{MPa}$ or higher was applied. ${ }^{14,32}$ Therefore, the axial load for equilibration in this study was chosen to reach an osmotic pressure of approximately $0.3 \mathrm{MPa}$, as the osmotic pressure range at rest in humans is $0.1-0.3 \mathrm{MPa}$ in vitro. ${ }^{33}$ Equilibration with $0.3 \mathrm{MPa}$ caused some water loss initially, resulting in an increased FCD and osmotic pressure at day 1. Nevertheless, after 28 days of culture the water content and FCD returned to that in freshly harvested tissue. While no statistically significant changes in the GAG content and histology were observed compared to day
1, it is possible that a small (quantitatively insignificant) amount of GAG was lost. As aggrecan is partly fragmented, even in healthy IVD tissue, ${ }^{26}$ fragments could have diffused out of the tissue between day 0 and 28. This GAG loss could have caused a decrease in FCD and osmotic pressure. Without a change in hydraulic pressure this would have resulted in a loss of water, but with a reduction of the tissue's volume accompanying the loss of GAGs, the drop in hydraulic pressure could have been equal or greater than the drop in osmotic pressure. This caused either no exchange of water or a slight influx into the tissue until osmotic and hydraulic pressure were again equal. Therefore, in hindsight $0.3 \mathrm{MPa}$ may have been a suboptimal equilibrium load, as self-regulation was necessary to maintain the tissue. Nevertheless, the extracellular matrix composition and cell viability remained statistically unchanged in long-term culture, thus the decrease in osmotic pressure was small and changes in tissue content were statistically insignificant.

However, the expression of some genes did change. The expression of main matrix component $A C A N$ decreased, like in some previous long-term NP cultures. ${ }^{30}$ Also in this respect, the $0.3 \mathrm{MPa}$ during equilibration may have been suboptimal, and an optimal pressure, at which both extracellular matrix and gene expression are maintained, may exist and should be explored. However, additional influential factors may also be considered. Previously, it has been shown that anabolic gene expression of isolated NP cells (NPCs) in hydrogels increases after dynamic hydrostatic loading, ${ }^{15,20}$ that mildly degenerated rat NPs show increased $A C A N$ expression after dynamic axial compression, ${ }^{34}$ and that unloaded caprine discs show a significantly lower $A C A N$ expression in their NPs than the NPs of loaded discs, ${ }^{22}$ if the applied forces are within the physiological range. Since both dynamic 
$1 \mathrm{~h}$
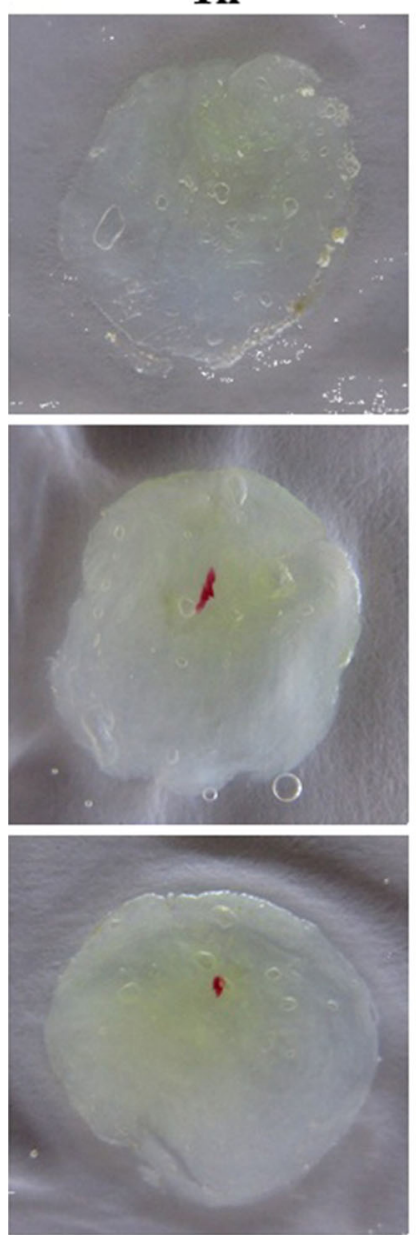

$5 \mathbf{h}$
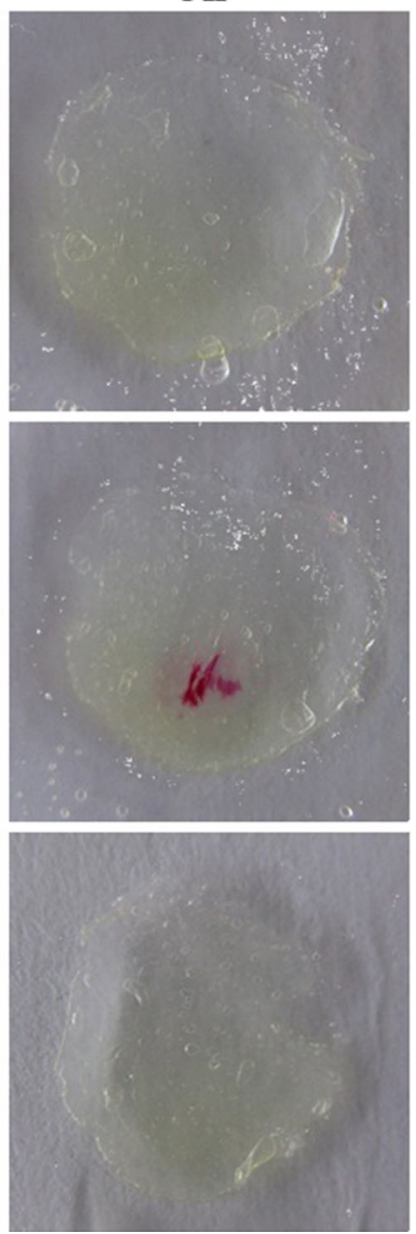

$17 \mathrm{~h}$

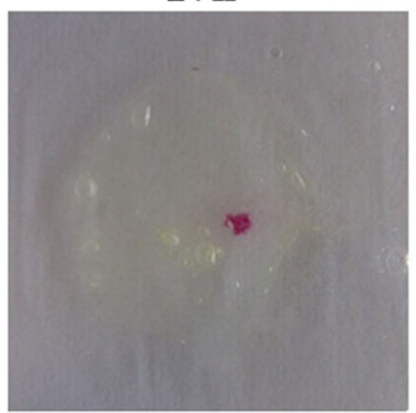

Top
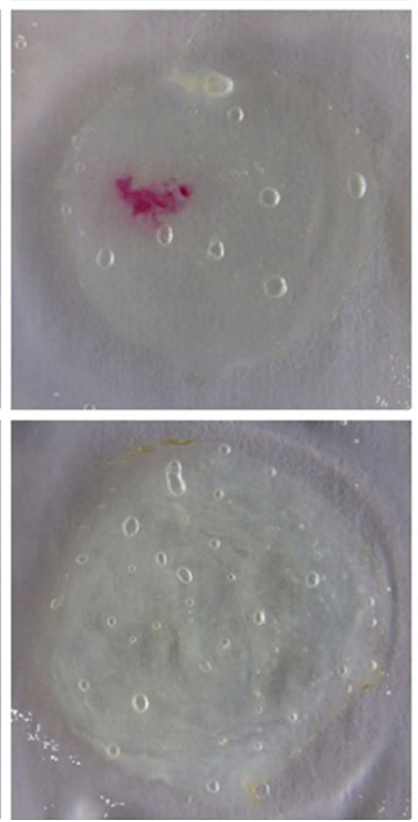

Middle

\section{Bottom}

FIGURE 6. Targeting injections. Diffusion was observed 1,5 or $17 \mathrm{~h}$ after injection of picrosirius red in the top, middle or bottom part of the sample.

hydrostatic loading and dynamic compression can be applied on the NP in this culture system, by transmission through or displacement of the sintered stainless steel plates, loading regimens can be used to mimic the physiological conditions and herewith possibly maintain $A C A N$ gene expression at native levels. Finally, gene expression profiles may be improved by lowering the $\mathrm{pH}$ to 7.1-7.2, as it has been shown that at this physiological $\mathrm{pH}$ the proteoglycan synthesis rate is highest in vitro, ${ }^{21}$ and by culturing in serum-free medium. ${ }^{24}$ Based on previous studies ${ }^{7,16,30}$ the oxygen concentration was chosen at $5 \%$ to create a physiological gradient towards the center of the NP. ${ }^{18}$

Needles with gauges of a wide range can be used to inject into the tissue through the injection port. Therefore, it is possible to inject controlled release hydrogels, large cells (e.g., notochordal cells) and therapeutics. In the current study sample heights were very similar, so that the deposition of the injected material was easily centralized in the core of the samples. In case that sample heights differ, some more care regarding the needle depth and skewedness is required to inject in the core.

In this study, PBS, Link-N and TNF- $\alpha$ were injected in bovine NP tissue to test if the tissue is able to respond in the culture system. Synthetic peptide Link-N has been shown to be a promising therapeutic agent for NP regeneration, as it increases proteoglycan synthesis, ${ }^{17} A C A N$ expression, and simultaneously decreases the expression of catabolic markers in isolated NPCs. ${ }^{6}$ Similarly, Link-N was able to increase proteoglycan synthesis in vitro in intact human IVDs. ${ }^{6}$ However, in the current study no increase in $A C A N$ expression was observed after two Link-N injections. The discrepancy between the results of the current study and that of Gawri et al. may be explained by the culture method. Link-N molecules are very small $(1.9 \mathrm{kDa})$ and therefore they can freely diffuse through the tissue. Unlike the study of Gawri et al. where Link-N, injected into the NP of a whole disc, is kept inside the disc by the rather impermeable AF and endplates, our system was not able to prevent Link-N diffusion out of the system. 
(a)

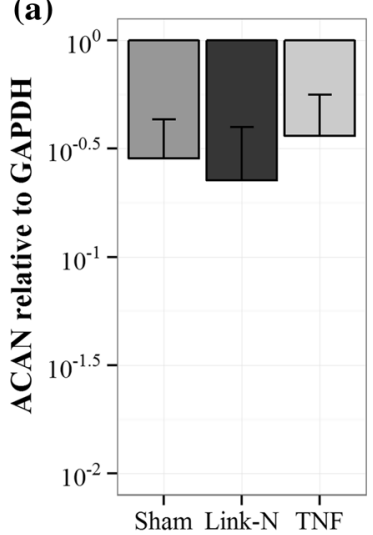

(d)

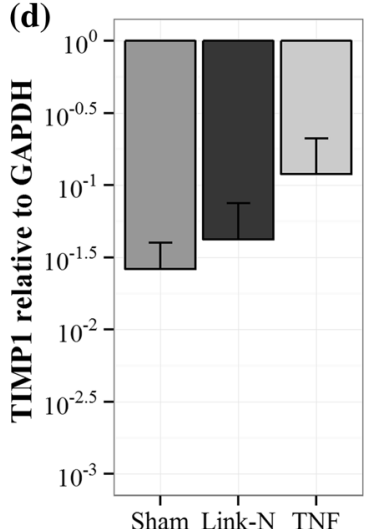

(b)

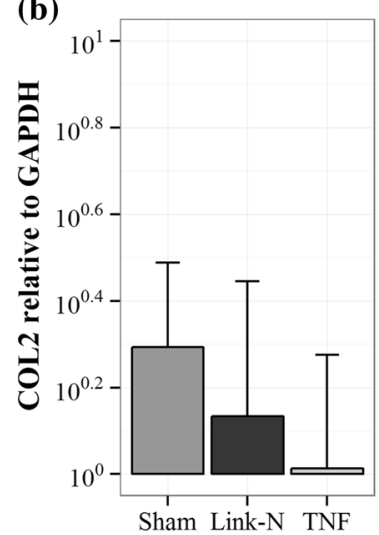

(e)

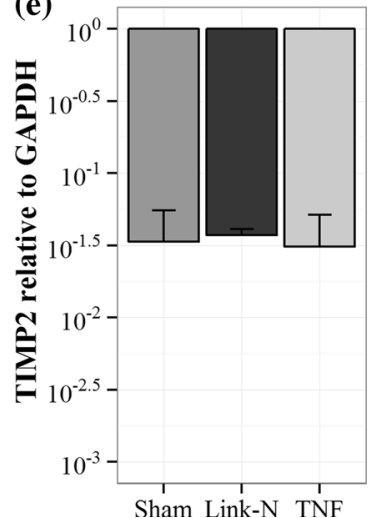

(c)

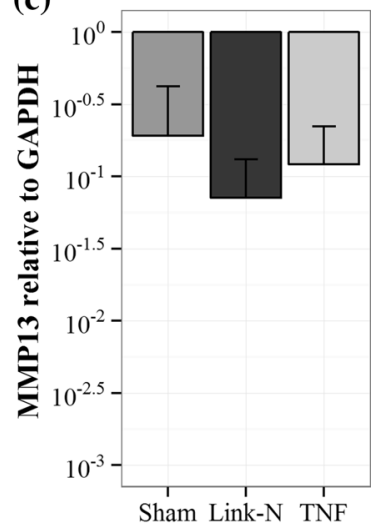

(f)

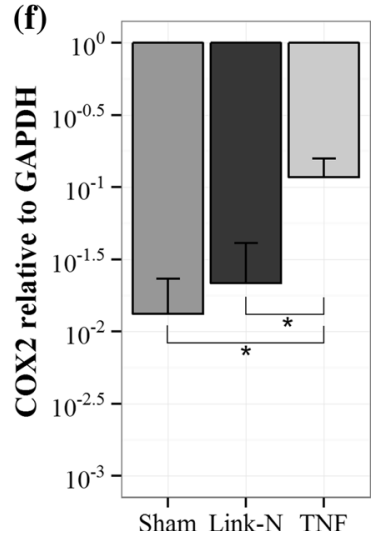

FIGURE 7. Gene expression after injections of Link-N and TNF- $\alpha$. The expression of (a) aggrecan, (b) collagen type II, (c) matrix metalloprotease 13, (d) tissue inhibitor of metalloprotease (TIMP) 1, (e) TIMP2, and (f) cyclooxygenase 2 relative to reference gene glyceraldehyde-3-phosphate dehydrogenase. Please note the logarithmic $y$-axis and error bars. $X$-axis $=$ injection group. Values are mean $\pm \mathrm{SD} ; n=3$ for sham; $n=4$ for Link-N; $n=5$ for TNF- $\alpha .{ }^{*} p<0.05$.

Furthermore, in the current study, the injected amount of Link-N was not corrected for the (very large) volume of culture medium, in which Link-N diffused. Picrosirius red, used for testing the injection port, has a similar molecular weight as Link-N and diffused throughout the whole tissue within $17 \mathrm{~h}$. In this respect, it is likely that the final tissue concentration of Link-N in the current study was below the effectiveness level. For future studies, it is recommended to inject a controlled release hydrogel containing Link-N, in order to keep Link-N available to the cells during the full period of culture. Alternatively, a larger growth factor like osteogenic protein-1 (OP-1; a.k.a. BMP-7) may be used. Due to their size, the diffusion of these molecules is expected to be slower.

TNF- $\alpha(17.5 \mathrm{kDa})$ is one of the major inflammatory cytokines measured during herniation and degeneration of the NP. ${ }^{25,35}$ In this study, TNF- $\alpha$ injections resulted in an increased $C O X 2$ expression compared to the sham and Link-N groups. Up regulation of $C O X 2$ expression in response to TNF- $\alpha$ stimulation is in accordance with literature that describes the effect of
$\mathrm{TNF}-\alpha$ on isolated $\mathrm{NPCs}^{29}$ or in tissue engineered $\mathrm{NP}{ }^{27}$ In addition to $\mathrm{COX} 2$ up regulation, the latter study showed down regulation of $A C A N$ expression after TNF- $\alpha$ supplementation, which was not observed in the current study. ${ }^{27}$ This discrepancy could be explained by the difference in experimental set-up between the studies: cells isolated from their native environment may not fully maintain their phenotype during the isolation procedure and/or they may behave differently when no native extracellular matrix is present. ${ }^{9}$ The differences between the studies emphasize the added value of culturing NP tissue compared to isolated NPC culture only. In these culture systems the NP tissue can be maintained and responsive under physiological conditions. IVD organ culture systems additionally include interactions with the other tissues of the IVD, but maintaining the tissue for longer periods is difficult. ${ }^{4,10}$ The in vivo testing of therapeutics is most attractive, but expensive and not ethical in early stages of research. ${ }^{1}$

In conclusion, the native biochemical content and cell viability of NP tissue were maintained when 
cultured at a fixed tissue volume after equilibration with an osmotic pressure of $0.3 \mathrm{MPa}$ for 28 days. In addition, injections of cytokine TNF- $\alpha$ showed that the tissue is responsive. This novel culture system can be used to culture NP explants in a very reproducible manner and to test potential regenerative therapies.

\section{ACKNOWLEDGEMENTS}

Financial support: This project was internally funded.

\section{OPEN ACCESS}

This article is distributed under the terms of the Creative Commons Attribution 4.0 International License (http://creativecommons.org/licenses/by/4.0/), which permits unrestricted use, distribution, and reproduction in any medium, provided you give appropriate credit to the original author(s) and the source, provide a link to the Creative Commons license, and indicate if changes were made.

\section{REFERENCES}

${ }^{1}$ Alini, M., S. M. Eisenstein, K. Ito, C. Little, A. A. Kettler, K. Masuda, J. Melrose, J. Ralphs, I. Stokes, and H. J. Wilke. Are animal models useful for studying human disc disorders/degeneration? Eur. Spine J. 17:2-19, 2008.

${ }^{2}$ Bergknut, N., J. P. H. J. Rutges, H.-J. C. Kranenburg, L. A. Smolders, R. Hagman, H.-J. Smidt, A.-S. Lagerstedt, L. C. Penning, G. Voorhout, H. A. W. Hazewinkel, G. C. M. Grinwis, L. B. Creemers, B. P. Meij, and W. J. A. Dhert. The $\operatorname{dog}$ as an animal model for intervertebral disc degeneration? Spine (Phila Pa. 1976) 37(351-8):2012, 2012.

${ }^{3}$ Cesarone, C. F., C. Bolognesi, and L. Santi. Improved microfluorometric DNA determination in biological material using 33258 Hoechst. Anal. Biochem. 100:188197, 1979.

${ }^{4}$ Chan, S. C. W., B. Gantenbein-Ritter, V. Y. L. Leung, D. Chan, K. M. C. Cheung, and K. Ito. Cryopreserved intervertebral disc with injected bone marrow-derived stromal cells: a feasibility study using organ culture. Spine J. 10:486-496, 2010.

${ }^{5}$ Farndale, R., D. Buttle, and A. Barrett. Improved quantitation and discrimination of sulphated glycosaminoglycans by use of dimethylmethylene blue. Biochim. Biophys. Acta 883:173-177, 1986.

${ }^{6}$ Gawri, R., J. Antoniou, J. Ouellet, W. Awwad, T. Steffen, P. Roughley, L. Haglund, and F. Mwale. Best paper NASS 2013: Link-N can stimulate proteoglycan synthesis in the degenerated human intervertebral discs. Eur. Cells Mater. 26:107-119, 2013.

${ }^{7}$ Gorth, D. J., K. E. Lothstein, J. A. Chiaro, M. J. Farrell, G. R. Dodge, D. M. Elliott, N. R. Malhotra, R. L. Mauck, and L. J. Smith. Hypoxic regulation of functional extracellular matrix elaboration by nucleus pulposus cells in long-Term agarose culture. J. Orthop. Res. 33:747-754, 2015.

${ }^{8}$ Huszar, G., J. Maiocco, and F. Naftolin. Monitoring of collagen and collagen fragments in chromatography of protein mixtures. Anal. Biochem. 105:424-429, 1980.

${ }^{9}$ Ishihara, H., and K. Warensjo. Proteoglycan synthesis in the intervertebral disk nucleus: the role of extracellular osmolality. Am. J. Physiol. 272:c1499-c1506, 1997.

${ }^{10}$ Korecki, C. L., J. J. MacLean, and J. C. Iatridis. Characterization of an in vitro intervertebral disc organ culture system. Eur. Spine J. 16:1029-1037, 2007.

${ }^{11}$ Le Maitre, C. L., J. A. Hoyland, and A. J. Freemont. Studies of human intervertebral disc cell function in a constrained in vitro tissue culture system. Spine (Phila. Pa. 1976) 29:1187-1195, 2004.

${ }^{12}$ Lewis, G. Nucleus pulposus replacement and regeneration/ repair technologies: present status and future prospects. $J$. Biomed. Mater. Res. B. Appl. Biomater. 100:1702-1720, 2012.

${ }^{13}$ Livak, K. J., and T. D. Schmittgen. Analysis of relative gene expression data using real-time quantitative PCR and the 2(-Delta Delta C(T)) Method. Methods 25:402-408, 2001.

${ }^{14}$ Lotz, J. C., A. H. Hsieh, A. L. Walsh, E. I. Palmer, and J. R. Chin. Mechanobiology of the intervertebral disc. Biochem. Soc. Trans. 30:853-858, 2002.

${ }^{15}$ Lyn, C., L. Maitre, J. Frain, A. P. Fotheringham, and A. J. Freemont. Human cells derived from degenerate intervertebral discs respond differently to those derived from nondegenerate intervertebral discs following application of dynamic hydrostatic pressure. Biorheology 45:563-575, 2008.

${ }^{16}$ Mwale, F., I. Ciobanu, D. Giannitsios, P. Roughley, T. Steffen, and J. Antoniou. Effect of oxygen levels on proteoglycan synthesis by intervertebral disc cells. Spine (Phila. Pa. 1976) 36:E131-E138, 2011

${ }^{17}$ Mwale, F., C. N. Demers, A. Petit, P. Roughley, A. R. Poole, T. Steffen, M. Aebi, and J. Antoniou. A synthetic peptide of link protein stimulates the biosynthesis of collagens II, IX and proteoglycan by cells of the intervertebral disc. J. Cell. Biochem. 88:1202-1213, 2003.

${ }^{18}$ Naqvi, S. M., and C. T. Buckley. Extracellular matrix production by nucleus pulposus and bone marrow stem cells in response to altered oxygen and glucose microenvironments. J. Anat. Epub, 2015.

${ }^{19}$ Narmoneva, D. A., H. S. Cheung, J. Y. Wang, D. S. Howell, and L. A. Setton. Altered swelling behavior of femoral cartilage following joint immobilization in a canine model. J. Orthop. Res. 20:83-91, 2002.

${ }^{20}$ Neidlinger-Wilke, C., K. Würtz, A. Liedert, C. Schmidt, W. Börm, A. Ignatius, H.-J. Wilke, and L. Claes. A threedimensional collagen matrix as a suitable culture system for the comparison of cyclic strain and hydrostatic pressure effects on intervertebral disc cells. J. Neurosurg. Spine 2:457-465, 2005

${ }^{21}$ Ohshima, H., and J. Urban. The effect of lactate and $\mathrm{pH}$ on proteoglycan and protein synthesis rates in the intervertebral disc. Spine (Phila. Pa. 1976) 17:1079-1082, 1992.

${ }^{22}$ Paul, C. P. L., H. A. Zuiderbaan, B. Z. Doulabi, A. J. van der Veen, P. M. van de Ven, T. H. Smit, M. N. Helder, B. J. van Royen, and M. G. Mullender. Simulated-physiological loading conditions preserve biological and mechanical properties of caprine lumbar intervertebral discs in ex vivo culture. PLoS One 7:29-34, 2012. 
${ }^{23} \mathrm{R}$ Core Team. R: A Language and Environment for Statistical Computing. 2014.

${ }^{24}$ Reza, A. T., and S. B. Nicoll. Serum-free, chemically defined medium with TGF-beta3 enhances functional properties of nucleus pulposus cell-laden carboxymethylcellulose hydrogel constructs. Biotechnol. Bioeng. 105:384-395, 2010.

${ }^{25}$ Risbud, M. V., and I. M. Shapiro. Role of cytokines in intervertebral disc degeneration: pain and disc content. Nat. Rev. Rheumatol. 10:44-56, 2014.

${ }^{26}$ Roughley, P. J., L. I. Melching, T. F. Heathfield, R. H. Pearce, and J. S. Mort. The structure and degradation of aggrecan in human intervertebral disc. Eur. Spine J. 15(Suppl 3):S326-S332, 2006.

${ }^{27}$ Séguin, C. A., M. Bojarski, R. M. Pilliar, P. J. Roughley, and R. A. Kandel. Differential regulation of matrix degrading enzymes in a TNFalpha-induced model of nucleus pulposus tissue degeneration. Matrix Biol. 25:409418, 2006.

${ }^{28}$ Stoddart, M. J., P. I. Furlong, A. Simpson, C. M. Davies, and R. G. Richards. A comparison of non-radioactive methods for assessing viability in ex vivo cultured cancellous bone: technical note. Eur. Cells Mater. 12:16-25, 2006.

${ }^{29}$ Studer, R. K., N. Vo, G. Sowa, C. Ondeck, and J. Kang. Human nucleus pulposus cells react to IL-6: independent actions and amplification of response to IL-1 and TNF- $\alpha$. Spine (Phila. Pa. 1976) 36:593-599, 2011.
${ }^{30}$ Van Dijk, B. G. M., E. Potier, and K. Ito. Long-term culture of bovine nucleus pulposus explants in a native environment. Spine J. 13:454-463, 2013.

${ }^{31}$ Walker, M. H., and D. G. Anderson. Molecular basis of intervertebral disc degeneration. Spine J. 4:158S-166S, 2004

${ }^{32}$ Wang, D. L., S.-D. Jiang, and L.-Y. Dai. Biologic response of the intervertebral disc to static and dynamic compression in vitro. Spine (Phila. Pa. 1976) 32:2521-2528, 2007.

${ }^{33}$ Wilke, H., P. Neef, M. Caimi, T. Hoogland, and L. Claes. New in vivo measurements of pressures in the intervertebral disc in daily life. Spine (Phila. Pa. 1976) 24:755-762, 1999.

${ }^{34}$ Wuertz, K., K. Godburn, J. J. MacLean, A. Barbir, J. S. Donnelly, P. J. Roughley, M. Alini, and J. C. Iatridis. In vivo remodeling of intervertebral discs in response to shortand long-term dynamic compression. J. Orthop. Res. 27:1235-1242, 2009.

${ }^{35}$ Wuertz, K., and L. Haglund. Inflammatory mediators in intervertebral disk degeneration and discogenic pain. Glob. Spine J. 3:175-184, 2013.

${ }^{36}$ Zhao, C.-Q., L.-M. Wang, L.-S. Jiang, and L.-Y. Dai. The cell biology of intervertebral disc aging and degeneration. Ageing Res. Rev. 6:247-261, 2007. 